\title{
Clinical and laboratory profiles of genital ulcers (sexually transmitted diseases) in a tertiary care center in northeastern India
}

\section{Romita Bachaspatimayum, Guite Zamzachin, Thangjam Bijayanti Devi}

\author{
Department of Dermatology, Venereology and Leprosy, RIMS, Imphal, India
}

Corresponding author: Dr. Romita Bachaspatimayum, E-mail: dr.romita.bachaspatimayum@gmail.com

\begin{abstract}
Background: Genital ulcers are defined as breaches in the continuity of the genital mucosa and/or skin. Sexually transmitted infections (STIs) that cause genital ulcer disease (GUD) are syphilis, chancroid, donovanosis, lymphogranuloma venereum (LGV), and herpes genitalis. This study aimed to investigate the clinical and laboratory profiles of STI-related genital ulcers. Materials and Methods: A cross-sectional two-year study was conducted on patients attending the Outpatient Department of Dermatology, Venereology and Leprosy in a tertiary care center in northeastern India. Selected were 95 patients who presented themselves with STI-related genital ulcers. Detailed history taking and examination were conducted with basic tests to assist the diagnosis. Results: The male-to-female ratio was 3.32:1, and the most common site was the glans and prepuce in males (28.77\%) and the labia majora and minora in females (36.36\%). 96.84\% of patients had superficial ulcers. The KOH mount was positive in 26 patients. The Tzanck smear was positive in 31 patients. RPR was positive in four. HIV was positive in eleven. Herpes genitalis (96.84\%) was the most common GUD. Mixed STIs were attested in 41.05\% of patients. Conclusion: GUD can take various forms of presentation. The available laboratory tests should be utilized. The possibility of mixed infections should always be kept in mind.
\end{abstract}

Key words: Genital ulcer disease; Herpes simplex virus; HIV

\section{INTRODUCTION}

Genital ulcers are defined as breaches in the continuity of the genital mucosa and/or skin. Genital ulcer disease (GUD) may be due to sexually transmitted infections (STIs), such as syphilis, chancroid, donovanosis, lymphogranuloma venereum (LGV), herpes genitalis, or non-STIs, such as traumatic ulcers, Behçet's disease, lichen planus, erythema multiforme, lichen sclerosis et atrophicus, bullous diseases, Fournier gangrene, and squamous cell carcinoma [1].

Documenting the etiological agents of GUD remains especially difficult as the relevant diagnostic tests are often unavailable or are misused. The etiological agent may not be found due to the patient self-medicating or because of the contamination of the ulcers. However, bedside and laboratory tests are, in early lesions, fairly sensitive and specific. A clinical diagnosis may be misleading because the increasing number of HIV coinfections and mixed infections often alter the morphology of the ulcers and the textbook description of GUD may not always be present. The ulcers do not remain confined to the genitalia and may be seen in extragenital sites due to changes in sexual behavioral patterns. Clinical diagnoses have been observed to be incorrect in around $40 \%$ of patients with GUD when compared to laboratory tests [1].

In view of the above loopholes in the diagnosis and management of GUD, it is important that a clinical diagnosis is reinforced by the laboratory facilities

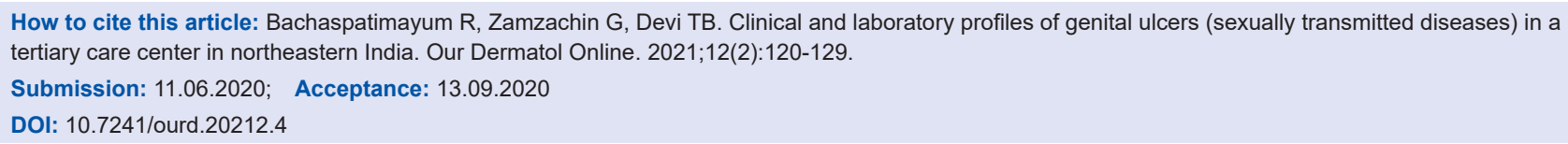


available at the institute of examination so that the newer trends of manifestation, if any, can be recognized and so that any HIV-correlated peculiarity of GUD can be detected. An accurate clinical diagnosis corroborated by laboratory findings will prevent inflicting unnecessary psychological trauma to the patient.

\section{MATERIALS AND METHODS}

A cross-sectional study was conducted on patients visiting the Outpatient Department of Dermatology, Venereology and Leprosy in collaboration with the Department of Microbiology, Regional Institute of Medical Sciences (RIMS), Imphal, Manipur, for a two-year period from October 2011 through September 2013.

A total of 95 cases of both sexes and all age groups who presented themselves with STI-related genital ulcers at the Outpatient Department of Dermatology, Venereology and Leprosy, RIMS Hospital, were selected from among all cases displaying genital ulcers after excluding non-STI-related genital ulcers. Clinically diagnosed STI-related genital ulcers for which the minimum laboratory investigations could not be completed due to poor patient compliance were also excluded from the study group. Ethical approval for this study was received from the Institutional Ethical Committee, RIMS, Imphal, Manipur.

After receiving a written informed consent from each of the patients, a detailed history was taken and recorded in a uniform predesigned proforma, followed by a thorough local and systemic examination as well as investigations such as genital swabs for KOH, wet mounts, Gram stain, Giemsa stain, Tzanck smear, and blood samples for VDRL and routine tests, including urine examination, tests for HIV, HBsAg, anti-HCV Ab, serology for herpes simplex virus 1 and 2 , and TPHA, wherever needed. The collected data was analyzed with descriptive statistics.

\section{RESULTS}

Among the total 95 cases studied, 73 (76.84\%) were males and 22 were females (23.16\%), giving a male-tofemale ratio of $3.32: 1$. The most common age group was $21-30$ years old $(34.73 \%)$.

The most common presentation among male patients was painful genital sore $(\mathrm{n}=22 ; 30.14 \%)$, followed by asymptomatic genital sores $(\mathrm{n}=14 ; 19.17 \%)$. The healthcare-seeking behavior in female patients was mainly due to pain $(\mathrm{n}=9 ; 40.90 \%)$ (Table 1$)$.

Most of the male patients $(\mathrm{n}=32 ; 43.83 \%)$ presented themselves between day 6 and 11 , in contrast to the female patients, among whom the majority $(\mathrm{n}=14$; $63.63 \%$ ) reported earlier, between day 0 and 5 after the onset of the disease. The mean duration of the disease was $11.88 \pm 13.299$ days in males and $11.14 \pm 16.994$ days in females (Table 2).

The most common site in males was the glans and prepuce ( $\mathrm{n}=21 ; 28.76 \%$ ) (Table 3$)$, while, in females, most ulcers appeared in both the labia majora and minora $(\mathrm{n}=8 ; 36.36 \%)$ (Fig. 1$)$.

Speculum examination of cervical lesions was skipped so as not to unnecessarily cause more paint to a suffering patient.

Table 1: Distribution of symptoms among males and females

\begin{tabular}{lcc}
\hline Symptoms & Male $\mathbf{n}(\%)$ & Female $\mathbf{n}(\%)$ \\
\hline Painful genital sore & $22(30.14)$ & $9(40.90)$ \\
Itching & $9(12.33)$ & $3(13.63)$ \\
Pain and itching & $6(8.22)$ & $0(0.00)$ \\
Pain and dysuria & $5(6.85)$ & $1(4.55)$ \\
Pain and discharge from the urethra or & $1(1.37)$ & $5(22.72)$ \\
vagina & & \\
Asymptomatic rash around the urethral & $1(1.37)$ & $0(0.00)$ \\
meatus & & \\
Pain with genital swelling & $0(0.00)$ & $1(4.55)$ \\
Genital sore with groin swelling & $1(1.37)$ & $0(0.00)$ \\
Genital sore with genital swelling & $1(1.37)$ & $1(4.55)$ \\
Genital sore with growth & $1(1.37)$ & $0(0.00)$ \\
Asymptomatic genital sores & $14(19.17)$ & $1(4.55)$ \\
Painless genital sore with dysuria & $1(1.37)$ & $0(0.00)$ \\
Itching with dysuria & $2(2.74)$ & $0(0.00)$ \\
No complaints (partner examination) & $1(1.37)$ & $1(4.55)$ \\
Skin eruption over the genitals & $7(9.59)$ & $0(0.00)$ \\
Painful anal erosion & $1(1.37)$ & $0(0.00)$ \\
Total & $73(100)$ & $22(100)$ \\
\hline
\end{tabular}

Table 2: Distribution of the time of persistence of lesions upon presentation

\begin{tabular}{lcc}
\hline Duration (days) & Male $\mathbf{n}(\%)$ & Female $\mathbf{n}(\%)$ \\
\hline $0-5$ & $22(30.14)$ & $14(63.63)$ \\
$6-11$ & $32(43.83)$ & $3(13.64)$ \\
$12-17$ & $7(9.59)$ & $2(9.09)$ \\
$18-23$ & $3(4.11)$ & $0(0.00)$ \\
$>23$ & $9(12.33)$ & $3(13.64)$ \\
Total & $73(100)$ & $22(100)$ \\
Prepuce, frenulum & $1(1.37)$ & \\
Prepuce, shaft, corona & $1(1.37)$ & \\
Shaft & $2(2.74)$ & \\
Periurethral area & $2(2.74)$ & \\
Perianal area & $1(1.37)$ & \\
Total & $73(100)$ & \\
\hline
\end{tabular}


The majority of patients had $1-3$ ulcers, $57.53 \%$ of males and $40.91 \%$ of females (Fig. 2). Among males, more than $16(21.92 \%)$ displayed a single ulcer, which was the most common presentation. The most common shape of ulcer was round ( $\mathrm{n}=29 ; 30.53 \%$ ). Ulcers had welldefined margins in $58(61.05 \%)$ patients, ill-defined in 36 $(37.90 \%)$, and undermined in one $(1.05 \%)$. Ninety-two (96.84\%) patients had superficial ulcers, while only three (3.16\%) had deep ulcers. A majority $(n=67 ; 70.53 \%)$ had clean ulcers. The surface was more erythematous in $29(30.53 \%)$ patients than in the others. Tenderness was present in only $34(35.79 \%)$ patients and induration in $13(13.68 \%)$. Associated vesicles were found in 36 (37.89\%) patients, associated discharge from the vagina in $9(40.9 \%)$, and associated urethral discharge in one male $(1.05 \%)$. Inguinal lymphadenopathy was present in $25(26.32 \%)$ patients, 16 males and 9 females, among which tenderness was present in nine males and four females (Table 4a).

The KOH mount was positive in $26(27.37 \%)$ patients, 19 males and 7 females. The Tzanck smear was positive in $31(32.63 \%)$ patients, 19 males and 12 females. RPR was positive in four (4.21\%) patients Table 4b. Gram stain showed mostly Gram-positive cocci and Gramnegative bacilli, besides Gram-positive bacilli (Table 5).

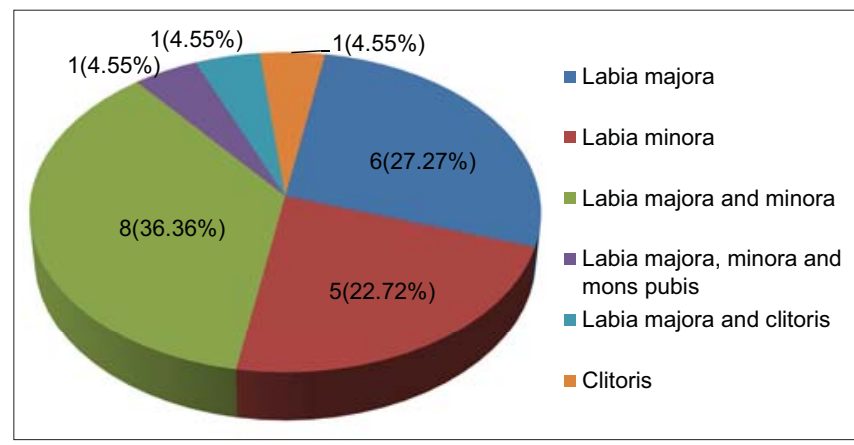

Figure 1: Distribution of ulcer sites in females.

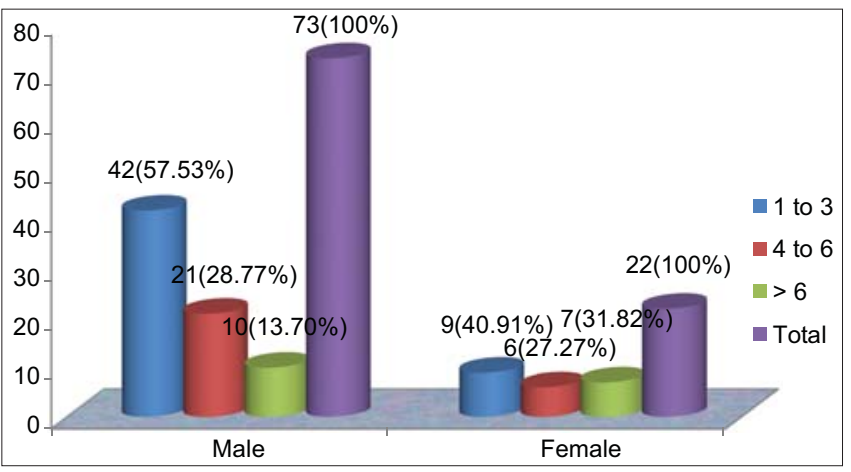

Figure 2: Distribution of the number of ulcers in both sexes.
There were no significant findings suggestive of microorganisms in $40(42.10 \%)$ patients. HIV was positive in $11(11.58 \%)$ patients; ten were positive and already on ART; one was recently diagnosed at the time of the study Table 4b. HCV antibody was positive in one HIV patient (1.05\%) on ART, while there was not a single patient positive for $\mathrm{HBsAg}$.

Table 3: Distribution of ulcer site in males

\begin{tabular}{lc}
\hline Ulcer site & Number (\%) \\
\hline Prepuce & $16(21.92)$ \\
Corona & $3(4.11)$ \\
Prepuce, corona & $2(2.74)$ \\
Glans & $15(20.55)$ \\
Glans, prepuce, corona & $1(1.37)$ \\
Glans, shaft & $3(4.11)$ \\
Glans, prepuce, shaft & $1(1.37)$ \\
Glans, prepuce & $21(28.76)$ \\
Glans, corona & $3(4.11)$ \\
Prepuce, scrotum & $1(1.37)$ \\
\hline
\end{tabular}

Table 4a: Other clinical characteristics of genital ulcers

\begin{tabular}{|c|c|c|c|}
\hline $\begin{array}{l}\text { Cutaneous } \\
\text { examination }\end{array}$ & Male, n (\%) & Female, n (\%) & Total, n (\%) \\
\hline \multicolumn{4}{|l|}{ Ulcer margin } \\
\hline Well-defined & $40(54.79)$ & $18(81.82)$ & $58(61.05)$ \\
\hline III-defined & $32(43.84)$ & $4(18.18)$ & $36(37.90)$ \\
\hline \multirow[t]{2}{*}{ Undermined } & $1(1.37)$ & $0(0)$ & $1(1.05)$ \\
\hline & $73(100)$ & $22(100)$ & $95(100)$ \\
\hline \multicolumn{4}{|l|}{ Surface } \\
\hline Clean & $53(72.60)$ & $14(63.64)$ & $67(70.53)$ \\
\hline Slough & $18(24.66)$ & $8(36.36)$ & $26(27.37)$ \\
\hline \multirow[t]{2}{*}{ Crusts } & $2(2.74)$ & $0(0)$ & $2(2.10)$ \\
\hline & $73(100)$ & $22(100)$ & $95(100)$ \\
\hline \multicolumn{4}{|l|}{ Depth } \\
\hline Superficial & $70(95.89)$ & $22(100)$ & $92(96.84)$ \\
\hline \multirow[t]{2}{*}{ Deep } & $3(4.11)$ & $0(0)$ & $3(3.16)$ \\
\hline & $73(100)$ & $22(100)$ & $95(100)$ \\
\hline \multicolumn{4}{|l|}{ Induration } \\
\hline Present & $8(10.96)$ & $5(22.73)$ & $13(13.68)$ \\
\hline \multirow[t]{2}{*}{ Absent } & 65 (89.04) & $17(77.27)$ & $82(86.32)$ \\
\hline & $73(100)$ & $22(100)$ & $95(100)$ \\
\hline \multicolumn{4}{|l|}{ Tenderness } \\
\hline Present & $20(27.40)$ & $14(63.64)$ & 34 (35.79) \\
\hline \multirow[t]{2}{*}{ Absent } & $53(72.60)$ & $8(36.36)$ & $61(64.21)$ \\
\hline & $73(100)$ & $22(100)$ & 95 (100) \\
\hline Vesicles & $22(30.14)$ & $14(63.64)$ & 36 (37.89) \\
\hline Present & $51(69.86)$ & $8(36.36)$ & 59 (62.11) \\
\hline \multirow[t]{2}{*}{ Absent } & ----------------- & --------------- & ---------------- \\
\hline & $73(100)$ & $22(100)$ & $95(100)$ \\
\hline \multicolumn{4}{|c|}{ Inguinal lymph node } \\
\hline Present & $16(21.92)$ & $9(40.90)$ & $25(26.32)$ \\
\hline \multirow[t]{2}{*}{ Absent } & 57 (78.08) & $13(59.10)$ & 70 (73.68) \\
\hline & $73(100)$ & $22(100)$ & $95(100)$ \\
\hline
\end{tabular}


Table 4b: Laboratory tests

\begin{tabular}{|c|c|c|c|}
\hline Test & Male, n (\%) & Female, n (\%) & Total, n (\%) \\
\hline \multicolumn{4}{|l|}{$\mathrm{KOH}$} \\
\hline Positive & $19(26.03)$ & $7(31.82)$ & $26(27.37)$ \\
\hline \multirow[t]{2}{*}{ Negative } & 54 (73.97) & $15(68.18)$ & 69 (72.63) \\
\hline & $73(100)$ & $22(100)$ & 95 (100) \\
\hline \multicolumn{4}{|l|}{ Tzanck smear } \\
\hline Positive & $19(26.03)$ & $12(54.55)$ & 31 (32.63) \\
\hline \multirow[t]{2}{*}{ Negative } & 54 (73.97) & $10(45.45)$ & 64 (67.37) \\
\hline & $73(100)$ & $22(100)$ & 95 (100) \\
\hline \multicolumn{4}{|l|}{ RPR } \\
\hline Reactive & $2(2.74)$ & $2(9.09)$ & $4(4.21)$ \\
\hline \multirow[t]{2}{*}{ Nonreactive } & $71(97.26)$ & 20 (90.91) & 91 (95.79) \\
\hline & 73 (100) & $22(100)$ & $95(100)$ \\
\hline \multicolumn{4}{|l|}{ HIV antibody } \\
\hline Reactive & $6(8.22)$ & $5(22.73)$ & $11(11.58)$ \\
\hline \multirow[t]{2}{*}{ Nonreactive } & 67 (91.78) & $17(77.27)$ & 84 (88.42) \\
\hline & $73(100)$ & $22(100)$ & 95 (100) \\
\hline
\end{tabular}

Table 5: Gram stain findings (Gm+: Gram-positive; Gm-: Gram-negative)

\begin{tabular}{lc}
\hline Gram stain & Number (\%) \\
\hline$G m+$ cocci singly & $10(10.53)$ \\
$G m+$ cocci in pairs & $6(6.32)$ \\
$G m+$ cocci in groups & $6(6.32)$ \\
$G m+$ cocci in groups and pairs & $3(3.16)$ \\
$G m+$ cocci in groups and chains & $3(3.16)$ \\
$G m+$ cocci and Gm+ coccobacilli & $1(1.05)$ \\
$G m+$ cocci in chains & $1(1.05)$ \\
$G m+$ coccobacilli in groups (rail track appearance) & $1(1.05)$ \\
Gm- bacilli & $8(8.42)$ \\
Gm+ cocci and Gm- bacilli & $8(8.42)$ \\
Gm- bacilli and Gm- diplococci & $3(3.16)$ \\
Gm- diplococci & $1(1.05)$ \\
Clue cells & $3(3.16)$ \\
Polymorphs & $1(1.05)$ \\
No significant findings & $40(42.10)$ \\
Total & $95(100)$ \\
\hline
\end{tabular}

Herpes genitalis ( $\mathrm{n}=92 ; 96.84 \%$ ) was the most common GUD, the second common being syphilis in $3(3.16 \%)$ patients (Table 6).

Mixed STI infections, including those with HIV and HCV, comprised 39 (41.05\%) patients. Among males, herpes genitalis was the most common GUD $(n=44)$. There were two cases of syphilis and one case per each of LGV and chancroid occurring as mixed infections with h. genitalis. In females, h. genitalis was the most common $(n=12)$ etiology of GUD, followed by h. genitalis with candidal vulvovaginitis $(\mathrm{n}=7)$. However, there was no case of donovanosis (Table 6).
Table 6: Distribution of the diagnosis of the various GUDs

\begin{tabular}{|c|c|c|c|}
\hline Diagnosis & Male $n(\%)$ & Female $\mathbf{n}(\%)$ & Total n (\%) \\
\hline H. genitalis & $44(60.27)$ & $12(54.55)$ & $56(58.95)$ \\
\hline Primary syphilis & $1(1.37)$ & $0(0)$ & $1(1.05)$ \\
\hline Secondary syphilis & $1(1.37)$ & $0(0)$ & $1(1.05)$ \\
\hline $\begin{array}{l}\text { Secondary syphilis with } \\
\text { candidal vulvovaginitis }\end{array}$ & $0(0)$ & $1(4.55)$ & $1(1.05)$ \\
\hline Chancroid, h. genitalis & $1(1.37)$ & $0(0)$ & $1(1.05)$ \\
\hline LGV with h. genitalis, HIV & $1(1.37)$ & $0(0)$ & $1(1.05)$ \\
\hline $\begin{array}{l}\text { H. genitalis with candidal } \\
\text { balanoposthitis }\end{array}$ & $16(21.92)$ & $0(0)$ & $16(16.85)$ \\
\hline $\begin{array}{l}\text { H. genitalis, genital warts, } \\
\text { BV, HIV }\end{array}$ & $0(0)$ & $1(4.55)$ & $1(1.05)$ \\
\hline H. genitalis, BV & $0(0)$ & $1(4.55)$ & $1(1.05)$ \\
\hline H. genitalis, genital warts & $2(2.74)$ & $0(0)$ & $2(2.11)$ \\
\hline $\begin{array}{l}\text { H. genitalis, NGU, } \\
\text { candidal balanoposthitis }\end{array}$ & $1(1.37)$ & $0(0)$ & $1(1.05)$ \\
\hline $\begin{array}{l}\text { H. genitalis, candidal } \\
\text { vulvovaginitis }\end{array}$ & $0(0)$ & $3(13.62)$ & $3(3.16)$ \\
\hline $\begin{array}{l}\text { H. genitalis, candidal } \\
\text { vulvovaginitis, HIV }\end{array}$ & $0(0)$ & $4(18.18)$ & $4(4.21)$ \\
\hline H. genitalis, NGU & $1(1.37)$ & $0(0)$ & $1(1.05)$ \\
\hline H. genitalis, HCV, HIV & $1(1.37)$ & $0(0)$ & $1(1.05)$ \\
\hline H. genitalis, HIV & $2(2.74)$ & $0(0)$ & $2(2.11)$ \\
\hline $\begin{array}{l}\text { H. genitalis, candidal } \\
\text { balanoposthitis, genital } \\
\text { warts, HIV }\end{array}$ & $2(2.74)$ & $0(0)$ & $2(2.11)$ \\
\hline Total & $73(100)$ & $22(100)$ & $95(100)$ \\
\hline
\end{tabular}

\section{DISCUSSION}

There are more than twenty pathogens transmissible through sexual intercourse but the exact magnitude of the burden of STIs is largely unknown due to the lack of in-depth studies, hindered by the stigma associated with STIs and by the lack of reinforcing clinical diagnosis with easy and quick diagnostic laboratory tests. In view of the rising prevalence of HIV/AIDS, proper control of STIs must be given due importance. It has been found that the presence of an untreated STI-ulcerative or nonulcerative-can increase risk of both the acquisition and transmission of HIV by a factor of ten [2]. A study by Desai et al. on the performance of STI syndromes against etiological diagnosis demonstrated that syndromic management based on genital ulcer syndrome (GUS) may miss around $85 \%$ of cases with active infection and lead to treatment of ulcers in $43 \%$ of cases in the absence of syphilis infection. Such a situation leads to the obvious financial burden of unindicated treatment while depriving the symptomatic cases of necessary care [3]. A study by Bailey et al. found that ulcers with bacterial or mixed etiologies were more likely to have detectable HIV-l compared to those with HSV or with unknown etiologies, and concluded that 
the presence of lesional HIV-1 in almost one-half of HIV-positive males underscores the importance of GUD in increasing HIV infectivity [4]. Choudhry et al. suggested that syndromic management of GUD is not very effective in identifying herpes genitalis and syphilis. They also found a high incidence of HIV seropositivity $(10.3 \%)$ in their study population, suggesting a close association of STI with HIV [5]. A study by Coovadia, Kharsany, et al. conducted in Durban, South Africa, demonstrated that, because of the lack of laboratory facilities in most STD clinics, microbial diagnosis is based on clinical criteria alone; their findings indicate that clinical and epidemiological features alone are not reliable in diagnosing the etiology of genital ulcers. Multiple ulcers, which are said to be characteristic of chancroid, were also noted in $36 \%$ (16/44) of patients with syphilis and in only 60\% (24/40) of those with chancroid. The presence of buboes and the length of the incubation period proved to be of some help in diagnosing chancroid [6]. In another study, the accuracy of a clinical diagnosis in men was $66 \%$ in lymphogranuloma venereum (LGV), 63\% in donovanosis, $42 \%$ in chancroid, $39 \%$ in genital herpes, $32 \%$ in primary syphilis, and $8 \%$ in mixed infections. In women, it was $94 \%$ in secondary syphilis, $83 \%$ in donovanosis, $60 \%$ in genital herpes, $58 \%$ in primary syphilis, $57 \%$ in chancroid, $40 \%$ in LGV, and $14 \%$ in mixed infections. Differences between clinical and laboratory diagnostic accuracies may reflect the similarities between the clinical appearance of the various causes of GUD, the presence of mixed infections, atypical ulceration due to longstanding disease, and insensitive laboratory tests [7].

Although there are more than 500 STD clinics in India, only 42 are functioning properly and collecting adequate records of cases. With the advocacy of the syndromic approach to the treatment of GUD and discharge, cases are diagnosed on the basis of flow charts, without laboratory aid, and are treated accordingly. This results in the provision of less information on HIV-positive cases among unregistered patients, which becomes a considerable social issue because HIV-positive cases remain unrecorded and become sources further propagating infection [8]. A study by DiCarlo and Martin demonstrated that the results of reaching an accurate clinical diagnosis of GUD were dependent on the clinician's skills and are thus influenced by factors such as previous experience, knowledge of epidemiological risk factors, and disease prevalence, due to which the results may not be generalized. They found that comparing individual signs underlined statistically significant differences between ulcers in chancroid, genital herpes, and primary syphilis. Despite the statistical significance of these differences, however, there was a considerable overlap between the three groups [9].

Behets et al., in a study to determine the etiology of genital ulcers in Antananarivo, Madagascar, using a multiplex polymerase chain reaction (M-PCR) assay to detect DNA targets from Haemophilus ducreyi, Treponema pallidum, and herpes simplex virus in a single ulcer specimen and to assess the accuracy of clinical diagnosis and locally performed laboratory tests for comparison with the M-PCR results of 196 patients, found that syphilis and chancroid were clinically diagnosed in $42.9 \%$ of patients, syphilis in $36.7 \%$, chancroid in $7.1 \%$, LGV in $4.1 \%$, syphilis and LGV in $4.1 \%$, scabies in $4.1 \%$, genital herpes in $0.5 \%$, and multiple agents in 3.1\% [10]. In HIV-infected patients, genital herpes can result in severe and atypical clinical presentations. Syphilis in an HIV patient appears to progress more rapidly through the clinical stages of syphilis and may often have an atypical clinical presentation or a refractory course after appropriate intramuscular penicillin, and lead to unusual serologic test results [11]. A study by Gopalkrishna et al. found that a majority of chlamydia-infected patients had syphilis (48\%) besides other concomitant sexually transmitted infections, such as gonorrhea, genital herpes simplex type 2 , condyloma acuminata, candidiasis, and bacterial vaginosis [12].

A study by Shaw et al. conducted in a rural Gambian community found that HSV2 positivity rose markedly with age in women while in men remained low in the younger age groups. In men, they found no association between HSV2 and the level of education or ethnicity [13]. In a study on rural Ugandans with genital ulcers, participants infected with HIV reported 26 episodes of genital ulcers per 100 person-years, compared with 7 per 100 person-years among those not infected [14]. A study by Sanchez et al. conducted in the Dominican Republic and Peru found that the clinical etiologic diagnosis of GUD was inaccurate and unsuitable as a basis for the management of genital ulcer lesions. Laboratory tests other than RPR are unavailable in many developing countries; even in industrialized countries, tests such as dark-field microscopy and H. ducreyi culture are troublesome to receive, and the latter is insensitive [15]. 
A study by Ahmed and Mbwana conducted in two Tanzanian cities found that HSV-2 was the most commonly identified agent in genital ulcer specimens with a high prevalence of HIV among STD patients. HSV-2 was detected at significantly higher rates among HIV-seropositive than HIV-seronegative patients with GUD [16]. A study by Renzi et al. on MSM (men who have sex with men) found a 1.7-fold increase in the risk of HIV acquisition among MSM who did not report herpes lesions or symptoms in the last twelve months and a low proportion of HSV-2-seropositive MSM who reported a history of genital herpes. Given the potential difficulty in recognizing reactivation of perianal herpes, they suggested that serological testing might be an important prevention strategy aimed at the identification of HSV-2-infected MSM [17].

One of the most critical drawbacks of diagnosing STIs through laboratory diagnostics is the need to send the specimens to a central reference laboratory for analysis, thus forcing the patient to return to receive the results. A significant number of patients do not return and are lost to follow up [18]. An STI study on a female Brazilian population by de Lima Soares et al. found that multiple infections were common and that $51 \%$ of women had at least one STI [19]. A study by Shepherd et al. conducted in Pune, India, found the cofactors in the susceptibility to HIV to include circumcision, urethritis, and genital ulceration [20]. Earlier, Zamzachin et al. conducted a study in the same setting and found the incidence of STI to be 3\% of the total OPD visits for skin issues, while VDRL reactivity gave a median percentage of $8.49 \%$ and HIV prevalence among STI patients gave a median percentage of 8.12\% [21]. A study by Shivaswamy, Thappa, et al. conducted in Mumbai found that, among patients with clinical evidence of genital herpes, $94.2 \%$ were positive for both HSV-1 and HSV-2. In cases of the first episode of herpes genitalis, 66\% were positive for HSV-1 and HSV-2, whereas in recurrent genital herpes, $96.4 \%$ were positive for HSV-1 and HSV-2. 72.6\% of patients with no history suggestive of genital herpes were seropositive for HSV-2 [22].

In India, the main strategy aimed at achieving effective management for people with established infections has been to integrate STD services into the existing health care system, with a special emphasis on integration at the primary health care (PHC) level. The National AIDS Control Organization (NACO) for case management at this level recommends syndromic management [23]. A study by Reynolds, Risbud, Shepherd, et al. found that the first six months following the estimated time of exposure to syphilis is the period characterized by the greatest risk of HIV-l infection compared to individuals who either have never had syphilis or who have had syphilis but more than six months have passed since the estimated time of syphilis exposure [24].

An evaluation by Creegan, Bauer, et al. of the relative sensitivities of the VDRL and TP-PA tests found that the sensitivity of the diagnostic strategy of VDRL confirmed by TP-PA was $71 \%$. Substituting RPR for VDRL in a subset of 51 patients produced the same sensitivity. The sensitivity of TP-PA as the first-line diagnostic was $86 \%$ [25]. In a study on genital ulcers in women by Gomes et al., the most frequent etiology was herpetic lesion followed by autoimmune ulcers. Histological diagnosis was conclusive in only $26.4 \%$ of patients. They found, therefore, that the etiologic diagnosis of herpetic ulcers is difficult to reach, even if a variety of diagnostic methods are applied [26].

The treatment of GUD is often based only on the patient's medical history, while physical examination is inaccurate. Tests specifically for the evaluation of genital ulcers include syphilis serology and either the DGI or DIF test for Treponema pallidum; the culture or antigen test for HSV; and the culture for Haemophilus ducreyi. Mandatory HIV testing should be performed on all patients with genital ulcers caused by T. pallidum or H. ducreyi and HSV. In most cases, health care providers based in developing countries must treat patients on the basis of clinical presentation and epidemiological circumstances since testing facilities are often unavailable [27]. A study by Richards, Krantz, et al. aimed to describe the healthcare-seeking behavior among patients with newly-acquired symptomatic genital herpes and found that the presence of exquisite tenderness as the chief complaint may impede the diagnosis in the absence of a careful genital examination, which underscores the need to use various laboratory methods, such as follow-up HSV serology, to confirm the diagnosis of HSV infection [28].

In studying the effects of genital ulcer disease and herpes simplex virus type 2 on the efficacy of male circumcision as HIV prevention, Gray, Serwadda, et al. suggested that ulcers prevented by circumcision are likely to be non-herpetic in origin. They also suggested that most of the reduction in the risk of HIV afforded by circumcision is attributable to the removal of vulnerable foreskin tissue that contains HIV target 
cells [29]. Nath and Thappa showed the importance of Tzanck smear in the rapid diagnosis of genital herpes lesions by identifying multinucleate giant cells, although with less sensitivity than by viral cultures, and the feasibility of undertaking histopathology occasionally in cases such as a chronic herpes infection in HIV-infected individuals with atypical disease morphology and clinical course [30]. Since HIV shares numerous aspects with other STIs-including modes of transmission, behavioral and other cofactors, and potential control measures-HIV prevention can logically be situated within the larger encompassing domain of STI control [31]. In a study conducted in Brazil, Barbosa et al. verified the association between C. trachomatis infection and gonorrhea with urethral discharge, highlighting that STIs are often transmitted by the same route and treating them may reduce the incidence of HIV and other STIs, which would be an important step in prevention, planning, and care [32].

A prospective study of genital ulcer disease by HopeRapp et al. in Paris found primary syphilis to be the most common (35\%) cause, followed by herpes genitalis $(27 \%)$ and chancroid (3\%). A high frequency of HIV infection $(27 \%)$ was found particularly in patients with primary syphilis (33\%). They stressed that no clinical characteristic is predictive of etiology, undermining the importance of performing a thorough microbiologic evaluation [33]. Not much data is available regarding the current status of STIs in India and how their epidemiological and clinical picture is being modified in the context of the ongoing HIV/AIDS epidemic. More care needs to be exercised in order to inculcate safe sex practices and, thereby, reduce the incidence of preventable STIs, since intercurrent STIs are known to hasten the progression of an HIV infection toward the stage of fully-developed AIDS [34].

In a study to determine the etiology of STIs in Maputo, Mozambique, Zimba et al. stressed that syndromic management (SM) guidelines need to be area-specific and based on the knowledge of the prevalence of etiological syndromes and their drug susceptibility. The overall prevalence of HIV-l and HIV-2 infection was $35 \%$. GUD was associated with a significantly higher HIV prevalence $(\mathrm{p}<0.001)$ [35]. A prospective study by Bala et al. found that the frequency of biological false positive (BFP) reactions with the VDRL test was quite low $(0.2 \%)$ and concluded that the TPHA test should be employed for the routine confirmation of a positive VDRL test irrespective of its titer, especially to accurately diagnose and confirm syphilis in cases with a titer less than 1:8. They further noted that some of the TPHA-positive cases with a VDRL result of less than 1:8 might have been treated cases of syphilis and, therefore, attempts should be made to differentiate between past and active infections [36].

The most common presentation among male patients was painful genital sores $(\mathrm{n}=22 ; 30.14 \%)$, followed by asymptomatic genital sores $(\mathrm{n}=14 ; 19.17 \%)$ and itching $(\mathrm{n}=9 ; 12.33 \%)$. The healthcare-seeking behavior in female patients was mainly due to pain $(\mathrm{n}=9 ; 40.90 \%)$, which were all herpetic cases, similarly to a study by Richards et al. [28]. Only one (1.37\%) male patient with herpes genitalis produced clear urethral discharge. Internal dysuria was present in nine (9.47\%) patients with herpes genitalis, out of which eight were males. Fourteen (19.17\%) male patients, one patient with secondary syphilis and the others with herpes genitalis, and one (4.55\%) female patient with herpes genitalis displayed asymptomatic GUD. Most ( $\mathrm{n}=32 ; 43.83 \%$ ) of male patients presented themselves between day 6 and 11, most frequently on day 7 ( $\mathrm{n}=24 ; 32.88 \%)$, among which the majority $(n=23)$ were herpetic. This was in contrast to females, among which the majority $(n=14 ; 63.63 \%)$ reported earlier, between day 0 and 5 of the onset of the disease. The mean duration of disease was $11.88 \pm 13.299$ days (mean \pm SD) in males and $11.14 \pm 16.994$ days in females with an overall mean of $11.71 \pm 14.145$ days, which is almost identical to a study by Hope-Rapp et al. [33]. Pain in herpes genitalis reaches its maximum intensity during day 7-1 1 [37].

The most common site in males was in the glans and prepuce ( $\mathrm{n}=21 ; 28.76 \%)$. In females, most ulcers appeared in both the labia majora and minora $(n=8$; $36.36 \%$ ), which may be due to the greater contact of these sites during sexual contact. A study by Gomes et al. found that a majority of female genital ulcers were in the midline near the clitoris or vaginal introitus [26].

Among male patients, more than 16 (21.92\%) displayed a single ulcer, which is the most common presentation, similarly to what was observed by Hope-Rapp et al. [33] Tenderness was present in only 34 (35.97\%) patients, which may be due to the superficial nature of most of the ulcers. Associated vesicles, mostly minute, were found in 36 (37.89\%) patients, almost identically to a study by Sanchez et al. [15], and associated discharge from the vagina in nine $(40.90 \%)$ patients. Inguinal lymphadenopathy was present in $25(26.32 \%)$ patients, which again mirrors other studies $[10,15]$. 
The KOH mount was positive in $26(27.37 \%)$ patients, 19 males and 7 females, highlighting the importance of attending not only to the complaint at hand but also to the surrounding areas in order to rule out the possibility of other associated STIs. Multiple infections were also found in a study by de Lima Soares [19]. Tzanck smear was positive in only 31 (32.63\%) cases, comparably to a study in Manaus, Brazilian Amazon, in which it was positive in $30.3 \%$ of GUD patients [38]; this, in turn, may be due to the fact that most of the patients presented themselves late, with a mean duration of 11.71 days. Besides, as described above, associated vesicles, mostly minute, were present in only 36 patients, which may likewise contribute to the lesser positivity of Tzanck smear. Indeed, Tzanck smear has a sensitivity of only 50\% [39], may be negative in older lesions, and is inapplicable to dry lesions and crusts [40].

The RPR test was positive in four $(4.21 \%)$ patients, among which TPHA was positive in three patients. One female patient with herpes genitalis, who was TPHAnegative, had a titer of as high as 1:64, which may be explained by the fact that acute biological false positive reactions are caused by herpes genitalis [41] and other viral infections [42]. The seroprevalence of syphilis in our study was $0.35 \%$, which is quite low compared to the $3.5 \%$ of a study in Delhi [36]. This may be due to the widespread use of penicillin injection for all infections in this part of the country, which may have contributed to the relatively low prevalence of syphilis and other bacterial STIs as well. Histopathological examination was not deemed the gold standard for diagnosis in one study of female genital ulcers, where a low accuracy rate was found [26]. However, biopsies of genital ulcers might be helpful in identifying the cause of unusual ulcers or those that do not respond to initial therapy [43].

Herpes genitalis ( $\mathrm{n}=92 ; 96.84 \%$ ) was the most common GUD in our study, similarly to other studies in different parts of the world $[5,26,37,39,44,45]$. The second most common cause was syphilis in three (3.15\%) patients. In most countries around the world, syphilis ranks as the second most frequent cause of GUD, with a worldwide prevalence of 2-25\% [16,39]. Hontelez et al. [46] opined that, since T. pallidum is susceptible to the commonly available antibiotics, increased antibiotic exposure would be expected to have a secondary effect on the prevalence of syphilis. In one study, primary syphilis was found to be the most frequent etiology of genital ulcerations in MSM [33].
There was only one $(1.05 \%)$ case per each of chancroid and LGV, both as mixed infections with herpes genitalis. Mixed etiologies were also observed in other studies [19,32]. There was no case of donovanosis in our study, which may be due to its low prevalence in this region, whereas it is endemic along the east coast of Orissa, Andhra Pradesh, and Tamil Nadu [47]. The decrease in the prevalence of bacterial GUD, particularly chancroid, may be due to the improved bacterial STD management as well as the improved HSV-2 diagnostics, which may suggest a relative increase in the role of HSV-2 as a cause of GUD [16].

\section{CONCLUSION}

GUDs can have various modes of presentation with varied symptomatology, while atypical cases are a diagnostic dilemma. GUDs should never be presumed to be due to a single etiological agent, and all available laboratory facilities within reach should be utilized as far as practicable.

\section{Statement of Human and Animal Rights}

All the procedures followed were in accordance with the ethical standards of the responsible committee on human experimentation (institutional and national) and with the 2008 revision of the Declaration of Helsinki of 1975.

\section{Statement of Informed Consent}

Informed consent for participation in this study was obtained from all patients.

\section{REFERENCES}

1. Sharma VK, Kumar U. Clinical Approach to Genital Ulcer Disease. In: Sharma VK, editor. Sexually Transmitted Diseases and AIDS. $2^{\text {nd }}$ Ed. New Delhi: VIVA Books; 2009. p. 768-73.

2. World Health Organization. Global Prevalence and Incidence of selected curable sexually transmitted Infections - overview and estimates. Geneva: World Health Organization; 2001. Report no.: (WHO)/HIV_AIDS/2001.02.

3. Desai VK, Kosambiya JK, Thakor HG, Umrigar D, Khandwala BR, Bhuyan KK. Prevalence of sexually transmitted infections and performance of STI syndromes against aetiological diagnosis, in female sex workers of red light area in Surat, India. Sex Transm Infect. 2003;79:111-5.

4. Paz-Bailey G, Sternberg M, Puren AJ, Steele L, Lewis DA. Determinants of HIV type 1 shedding from genital ulcers among men in South Africa. Clin Infect Dis. 2010;50:1060-7.

5. Choudhry S, Ramachandran VG, Das S, Bhattacharya SN, Mogha NS. Pattern of sexually transmitted infections and performance of syndromic management against etiological diagnosis in patients attending the sexually transmitted infection clinic of a tertiary care hospital. Indian J Sex Transm Dis AIDS. 
2010;31:104-8

6. Coovadia YM, Kharsany A, Hoosen A. The microbial aetiology of genital ulcers in black men in Durban, South Africa. Genitourin Med. 1985;61:266-9.

7. O'Farrell N, Hoosen AA, Coetzee KD, van den Ende J. Genital ulcer disease: accuracy of clinical diagnosis and strategies to improve control in Durban, South Africa. Genitourin Med. 1994;70:7-11.

8. Bhargava R, Mathur D, Bhargava P. Syndromic management of genital ulcer disease--a critical appraisal. Genitourin Med. 1996;72:148-9.

9. DiCarlo RP, Martin DH. The clinical diagnosis of genital ulcer disease in men. Clin Infect Dis. 1997;25:292-8.

10. Behets FM, Andriamiadana J, Randrianasolo D, Randriamanga R, Rasamilalao D, Chen CY, et al. Chancroid, primary syphilis, genital herpes, and lymphogranuloma venereum in Antananarivo, Madagascar. J Infect Dis. 1999;180:1382-5.

11. Czelusta A, Yen-Moore A, van der Straten M, Carrasco D, Tyring SK. An overview of sexually transmitted diseases. Part III. Sexually transmitted diseases in HIV-infected patients. J Am Acad Dermatol. 2000;43:409-32.

12. Gopalkrishna V, Aggarwal N, Malhotra VL, Koranne RV, Mohan VP, Mittal A, et al. Chlamydia trachomatis and human papilloma virus infection in Indian women with sexually transmitted diseases and cervical precancerous and cancerous lesions. Clin Microbiol Infect. 2000;6:88-93.

13. Shaw M, van der Sande M, West B, Paine K, Ceesay S, Bailey R, et al. Prevalence of herpes simplex type 2 and syphilis serology among young adults in a rural Gambian community. Sex Transm Infect. 2001;77:358-65.

14. Klitsch M. Many rural Ugandans with genital ulcers fail to seek health treatment or to inform their sexual partners. International Family Planning Perspectives. 2002;26:47.

15. Sanchez J, Volquez C, Totten PA, Campos PE, Ryan C, Catlin M, et al. The etiology and management of genital ulcers in the Dominican Republic and Peru. Sex Transm Dis. 2002;29:559-67.

16. Ahmed HJ, Mbwana J, Gunnarsson E, Ahlman K, Guerino C, Svensson LA, et al. Etiology of genital ulcer disease and association with human immunodeficiency virus infection in two Tanzanian cities. Sex Transm Dis. 2003;30:114-9.

17. Renzi C, Douglas JM, Foster M, Critchlow CW, Ashley-Morrow R, Buchbinder SP, et al. Herpes simplex virus type 2 infection as a risk factor for human immunodeficiency virus acquisition in men who have sex with men. J Infect Dis. 2003;187:19-25.

18. Sahin-Hodoglugil NN, Woods R, Pettifor A, Walsh J. A comparison of cost-effectiveness of three protocols for diagnosis and treatment of gonococcal and chlamydial infections in women in Africa. Sex Transm Dis. 2003;30:455-69.

19. de Lima Soares, de Mesquita AMTS, Cavalcante FGT, Silva ZP, Hora V, Diedrich T, et al. Sexually transmitted infections in a female population in rural north-east Brazil: prevalence, morbidity and risk factors. Trop Med Int Health. 2003;8:595-603.

20. Shepherd ME, Gangakhedkar RR, Sahay S, Reynolds SJ, Ghate MV, Risbud AR, et al. Incident HIV infection among men attending STD clinics in Pune, India: pathways to disparity and interventions to enhance equity. J Health Popul Nutr. 2003;21:251-63.

21. Zamzachin G, Singh NB, Devi TB. STD trends in regional institute of medical sciences, Manipur. Indian J Dermatol Venereol Leprol. 2003;69:151-3

22. Shivaswamy KN, Thappa DM, Jaisankar TJ, Sujatha S. High seroprevalence of HSV-1 and HSV-2 in STD clinic attendees and non-high risk controls: a case control study at a referral hospital in South India. Indian J Dermatol Venereol Leprol. 2005;71:26-30.

23. Thappa DM. Evolution of venereology in India. Indian J Dermatol Venereol Leprol. 2006;72:187-96.

24. Reynolds SJ, Risbud AR, Shepherd ME, Rompalo AM, Ghate MV, Godbole SV, et al. High rates of syphilis among STI patients are contributing to the spread of HIV-1 in India. Sex Transm Infect. 2006;82:121-6.
25. Creegan L, Bauer HM, Samuel MC, Klausner J, Liska S, Bolan G. An evaluation of the relative sensitivities of the venereal disease research laboratory test and the Treponema pallidum particle agglutination test among patients diagnosed with primary syphilis. Sex Transm Dis. 2007;34:1016-18.

26. Gomes CMM, Giraldo PC, de Assis Moraes Gomes F, Amaral R, Passos MRL, da Silveira Gonçalves AK. Genital ulcers in women: clinical, microbiologic and histopathologic characteristics. Braz J Infect Dis. 2007;11:254-60.

27. Karthikeyan K. Recent advances in management of genital ulcer disease and anogenital warts. Dermatol Ther. 2008;21:196-204.

28. Richards J, Krantz E, Selke S, Wald A. Healthcare seeking and sexual behavior among patients with symptomatic newly acquired genital herpes. Sex Transm Dis. 2008;35:1015-21.

29. Gray RH, Serwadda D, Tobian AAR, Chen MZ, Makumbi F, Suntoke T, et al. Effects of genital ulcer disease and herpes simplex virus type 2 on the efficacy of male circumcision for HIV prevention: analyses from the Rakai trials. PLoS Med. 2009;6:e1000187.

30. Nath AK, Thappa DM. Newer trends in the management of genital herpes. Indian J Dermatol Venereol Leprol. 2009;75:566-74.

31. Steen R, Wi TE, Kamali A, Ndowa F. Control of sexually transmitted infections and prevention of HIV transmission: mending a fractured paradigm. Bull World Health Organ. 2009;87:858-65.

32. Barbosa MJ, Moherdaui F, Pinto VM, Ribeiro D, Cleuton M, Miranda AE. Prevalence of Neisseria gonorrhoeae and Chlamydia trachomatis infection in men attending STD clinics in Brazil. Rev Soc Bras Med Trop. 2010;43:500-3.

33. Hope-Rapp E, Anyfantakis V, Fouéré S, Bonhomme P, Louison JB, de Marsac TT, et al. Etiology of genital ulcer disease. A prospective study of 278 cases seen in an STD clinic in Paris. Sex Transm Dis. 2010;37:153-8.

34. Banerjee S, Halder S, Halder A. Trend of sexually transmitted infections in HIV seropositive and seronegative males: a comparative study at a tertiary care hospital of north east India. Indian J Dermatol. 2011;56:239-41.

35. Zimba TF, Apalata T, Sturm WA, Moodley P. Aetiology of sexually transmitted infections in Maputo, Mozambique. J Infect Dev Ctries. 2011;5:41-7.

36. Bala M, Toor A, Malhotra M, Kakran M, Muralidhar S, Ramesh V. Evaluation of the usefulness of Treponema pallidum hemagglutination test in the diagnosis of syphilis in weak reactive venereal disease research laboratory sera. Indian J Sex Transm Dis AIDS. 2012;33:102-6.

37. Corey L, Wald A. Genital herpes. In: Holmes KK, Mardh PA, Sparling PF, Lemon SM, Stamm WE, Piot P, Wasserheit JN, editors. Sexually transmitted diseases. $3^{\text {rd }}$ Ed. United States of America: McGraw-Hill Companies; 1999. p. 285-312.

38. Naveca FG, Sabidó M, de Almeida TAP, Veras EA, del Carmen Contreras Mejía M, Galban E, et al. Etiology of genital ulcer disease in a sexually transmitted infection reference center in Manaus, Brazilian Amazon. 2013. PLoS One. 2013;8:e63953.

39. Chernesky MA. Laboratory services for sexually transmitted diseases: overview and recent developments. In: Holmes KK, Mardh PA, Sparling PF, Lemon SM, Stamm WE, Piot P, Wasserheit JN, editors. Sexually transmitted diseases. $3^{\text {rd }}$ Ed. United States of America: McGraw-Hill Companies; 1999. p. 1281-94.

40. Sundharam JA. Viral and miscellaneous sexually transmitted diseases. In: Sharma VK, editor. Sexually Transmitted Diseases and AIDS. $2^{\text {nd }}$ Ed. New Delhi: VIVA Books; 2009. p. 407-86.

41. Wolf K, Johnson RA. Sexually transmitted infection. In: Sydor AM, Englis MR, editors. Fitzpatrick's Color Atlas \& Synopsis of Clinical Dermatology. $6^{\text {th }}$ Ed. United States of America: McGraw-Hill Companies; 2009. p. 896-941.

42. Vajpayee M, Mathur P. Laboratory diagnosis of syphilis. In: Sharma VK, editor. Sexually Transmitted Diseases and AIDS. $2^{\text {nd }}$ Ed. New Delhi: VIVA Books; 2009. p.303-16.

43. Sen P. A syndromic approach to the management of genital ulcers. 


\section{www.odermatol.com}

The Singapore Family Physician. 2013;39:40-7.

44. Bruisten SM, Cairo I, Fennema H, Pijl A, Buimer M, Peerbooms PG, et al. Diagnosing genital ulcer disease in a clinic for sexually transmitted diseases in Amsterdam, The Netherlands. J Clin Microbiol. 2001;39:601-5.

45. Roett MA, Mayor MT, Uduhiri KA. Diagnosis and management of genital ulcers. Am Fam Physician. 2012;85:254-62.

46. Hontelez JAC, van der Loeff MFS, Peterson I, Peterson K, Ahadzie B, Cotten M, et al. Declining trend of serological syphilis among genitourinary medicine patients in the Gambia, West Africa. Sex Transm Dis. 2009;36:745-9.
47. Ganesh R. Donovanosis. In: Sharma VK, editor. Sexually transmitted diseases and AIDS. $2^{\text {nd }}$ Ed. New Delhi: VIVA Books; 2009. p.347-55.

Copyright by Romita Bachaspatimayum, et al. This is an open-access article distributed under the terms of the Creative Commons Attribution License, which permits unrestricted use, distribution, and reproduction in any medium, provided the original author and source are credited.

Source of Support: Nil, Conflict of Interest: None declared. 